Adv Biochem Engin/Biotechnol

DOI: $10.1007 / 10 \_2010 \_88$

(C) Springer-Verlag Berlin Heidelberg 2010

\title{
Biology of Human Hair: Know Your Hair to Control It
}

\author{
Rita Araújo, Margarida Fernandes, Artur Cavaco-Paulo and \\ Andreia Gomes
}

\begin{abstract}
Hair can be engineered at different levels - its structure and surfacethrough modification of its constituent molecules, in particular proteins, but also the hair follicle (HF) can be genetically altered, in particular with the advent of siRNA-based applications. General aspects of hair biology are reviewed, as well as the most recent contributions to understanding hair pigmentation and the regulation of hair development. Focus will also be placed on the techniques developed specifically for delivering compounds of varying chemical nature to the HF, indicating methods for genetic/biochemical modulation of HF components for the treatment of hair diseases. Finally, hair fiber structure and chemical characteristics will be discussed as targets for keratin surface functionalization.
\end{abstract}

Keywords Follicular morphogenesis - Hair follicle • Hair life cycle • Keratin

\section{Contents}

1 Structure and Morphology of Human Hair

2 Biology of Human Hair

2.1 Hair Follicle Anatomy.

2.2 Hair Follicle Morphogenesis

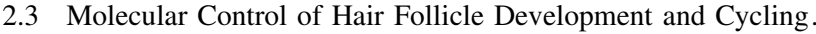

3 Strategies for Cosmetic and Clinical Purposes

3.1 Treatments of Hair Growth Disorders: Room for Improvement

3.2 Modifications of Hair Fiber Surface and Structure.

4 Final Remarks.

References

R. Araújo and A. Gomes ( $\triangle)$

CBMA-Centre of Molecular and Environmental Biology, Department of Biology,

University of Minho, Campus of Gualtar, 4710-057 Braga, Portugal

e-mail: agomes@bio.uminho.pt

R. Araújo, M. Fernandes and A. Cavaco-Paulo

Centre of Textile Engineering, University of Minho, Campus of Azurém, 4800-058

Guimarães, Portugal 


\section{Structure and Morphology of Human Hair}

Human hair is mainly composed of fibrous $\alpha$-keratin proteins. Hair fibres are not continuous in their full length, but rather result from compact groups of cells within the fibre follicle, from which three further basic morphological components of hair structure originate: the multicellular cuticle sheath, the fibrous cortex and the medulla $[1,2]$.

At the follicular level, a single layer of cells gives rise to the cuticle, a protective layer covering the core of the fibres. It is mainly composed of $\beta$-keratins and displays a scaled structure, possessing between seven and ten superimposed layers with the cuticle edges pointing toward the tip of the fibre [3]. The outer surface of the culticle's scale cells is coated by a thin membrane called the epicuticle, which covers the cysteine-rich exocuticle, a constituent that contains most of the cysteine residues present in the scales [4]. Finally, there is the endocuticle, which is located at the interface of the cortex and is mainly composed of the remaining cell organelles. Endocuticle consists of proteins that, unlike those found in other parts of the hair fibre, have very low sulphur content; thus, it is poor in cysteine, which causes the endocuticle of the scales to swell considerably more in water than the cysteine-rich exocuticle. This might explain the pronounced projection of the scales and the tendency for wool felting in the presence of water [5].

The cuticle tightly encircles the cortex that forms the most voluminous part and the heart of the hair fibre. The cortex is made up of cortical cells, which comprise the macrofibrils, long filaments oriented parallel to the axis of the fibre. Each macrofibril consists of intermediate filaments (IF), known also as microfibrils, and the matrix $[6,7]$. It has been established that the molecules that aggregate to form the IFs in keratin fibres are type I and type II keratin chains, arranged parallel to one another and in the axial register. After the formation of the $\alpha$-helices, it is believed that the two types of chains associate to form a dimer, which then aggregates with another dimer to form a tetramer. Finally, the formation of a pseudo-hexagonal structure (the IFs structure) occurs by the association of seven or eight tetramers. Type I chains are net acidic, with $\mathrm{p} I$ values in the range of 4.5-5.5, while type II chains are neutral-basic with $\mathrm{p} I$ around 6.5-7.5 [8-11]. As a consequence, the IFs are low in cystine $(\sim 6 \%)$, whereas the matrix contains up to $20 \%$ of total amino acid residues [12-14].

The matrix proteins that surround the IFs through intermolecular disulfide bonds act as a disulfide crosslinker holding the cortical superstructure together and conferring high mechanical strength, inertness and rigidity to keratin fibres. High sulphur proteins, ultra-high sulphur proteins and high glycine-tyrosine proteins are present in matrix proteins ( $\gamma$-keratins), depending on their cysteine, tyrosine and glycine content $[1,4,15,16]$.

Apart from albinos, all normal humans have melanin hair pigmentation, whatever the colour. Dispersed throughout the structure of the cortex in granular form are the melanin pigment particles. The number, chemical characteristics and distribution pattern of these cells determine the colour of the hair [2]. The actual 


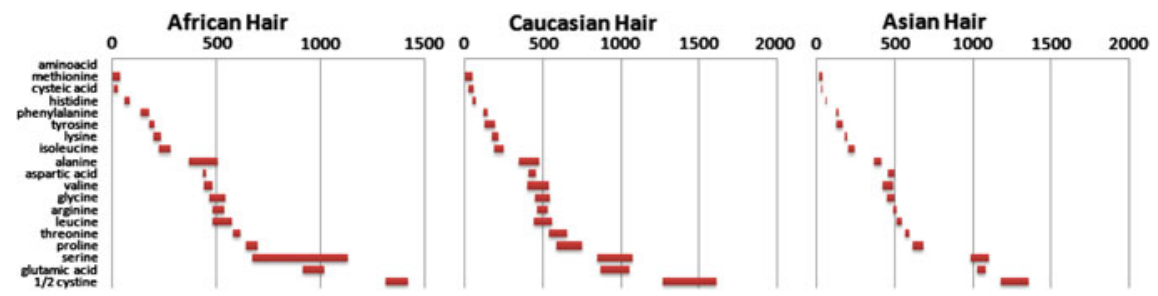

Fig. 1 Amino acid content of human hair of diverse ethnic origins $(\mu \mathrm{M} / \mathrm{g})$ (adapted from $[1,2$, 18, 19])

shade of colour in each individual depends not only on which melanin is present, but also its quantity and the site, number and shape of pigment granules in the hair cortex $(\mathrm{Cx})[17]$.

Vacuolated cells may also be present along the axis of coarser $\alpha$-keratin fibres, forming the medulla. These cells generally constitute only a small percentage of the mass of hair and are believed to contribute negligibly to the mechanical properties of human hair fibres. Physically, the medulla forms the empty space of the fibre $[4,7]$.

Like all polymeric structures, keratin fibres consist of long, tightly bound molecular chains held together in many different ways from covalent bonds to weaker interactions such as hydrogen bonds, Coloumbic interactions, van der Walls interactions and, when water is present, hydrophobic bonds. Hair reactivity is complex and depends not only on the presence of reactive groups in the fibre, but also on their availability. The latter is significantly affected by fibre morphology and molecular structure [2]. Hair is mostly proteinaceous in nature, while structural lipids and other materials represent only a minor fraction of its constituents.

Human hair is usually categorised ethnically into three major distinct groups: Asian, Caucasian and African. Looking from the perspective of biological variability, environmental effects and diversity of fibre texture, it is remarkable how uniformly the amino acid makeup of protein components is across ethnic groups. The amino acid makeup of the protein components was reviewed by Wolfram and is depicted in Fig. 1 [1, 2, 18, 19].

\section{Biology of Human Hair}

Hair is an important feature of mammalians, where hair shafts fulfill a number of different functions such as thermoregulation, collection of sensory information, protection against environmental trauma, social communication and camouflage. Each of us displays an estimated total number of 5 million hair follicles (HF), of which $80,000-150,000$ are located on the scalp [20]. 


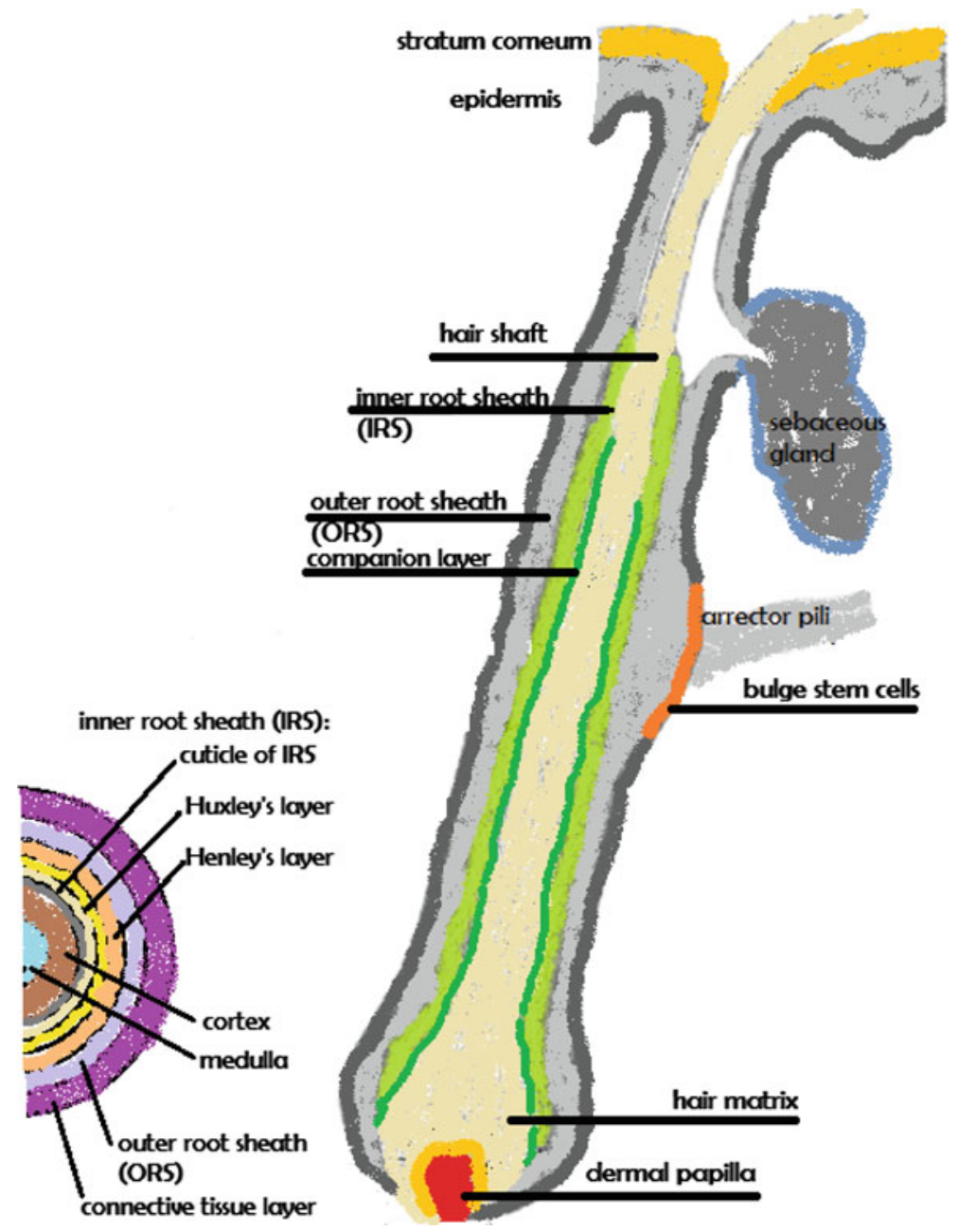

Fig. 2 The human hair follicle: structure, main functional areas and concentrical layers, which constitute the typical hair

The HF (Fig. 2) is one of the most complex mini-organs of the human body with the capacity to reconstitute itself. During postnatal life, HFs show patterns of cyclic activity with periods of active growth and hair production (anagen), apoptosis-driven involution (catagen) and relative resting (telogen) [21]. These cyclic changes involve rapid remodeling of both epithelial and dermal components and suggest the presence of intrinsic stem cells. Stem cells isolated from the bulge area possess high proliferative potential in vitro [22] and the capacity to repopulate HFs, sebaceous glands and epidermis in vivo [23-27]. These transformations are 
regulated by variations in the local milieu, based on changes in expression and/or activity of many cytokines, hormones, enzymes, neurotransmitters and their cognate receptors as well as of transcription factors that have become recognised as key mediators of HF cycling.

\subsection{Hair Follicle Anatomy}

The HF results of interactions between epithelial, mesenchymal and neuroectodermal cell populations as well as transient migratory cells.

The epithelium is divided into an upper permanent region, distal to the arrector pili muscle and an inferior region that includes the hair bulb (Fig. 2) [28]. Each HF is composed of nine distinctive epidermal layers: hair matrix (Mx), medulla (M), $\mathrm{Cx}$, hair cuticle $(\mathrm{Ce})$, cuticle of the inner root sheath $(\mathrm{Ci})$, Huxley's layer $(\mathrm{Hx})$, Henle's layer (He), companion layer ( $\mathrm{Cp}$ ) and outer root sheath (ORS), arranged concentrically from core to periphery, as well as two dermal tissues: dermal papilla (DP) and dermal sheath. Among these tissues, only the medulla is optional, given that some hairs have no medulla, whereas in others it is relatively large. The $\mathrm{Cx}$ and $\mathrm{Ce}$ constitute the major part of the hair shaft that penetrates the skin. Both $\mathrm{Cx}$ and $\mathrm{Ce}$ tissues undergo heavy keratinization to form the solid hair shaft. The three concentric layers located externally to the shaft constitute the inner root sheath (IRS), which is thought to support the growth and differentiation of the shaft. The innermost layer of the IRS, called the $\mathrm{Ci}$, consists of thin overlapping scales facing the Ce. The Hx layer is the last layer to undergo keratinization. This layer may help other keratinized cells in terms of nutritional and informational support. Importantly, $\mathrm{Hx}$ is known to contribute to relieving the distortion caused by uneven keratinization of the shaft, which occurs in curly hair, for example. On the other hand, the He layer keratinizes at a very early phase of hair growth so these keratinized cells are visible at a positionally low level of the HF. He layer provides mechanical support to the most delicate part of the HF in the early stages of its development.

Located within the hair bulb is a population of cells with the highest proliferation rate in the human body: the keratinocytes of the Mx. These can differentiate into trichocytes or cells of the IRS. The hair bulb in the anagen phase functions as a hair shaft producer and provides the hair shaft's trichocytes with characteristic melanin granules. The ORS, $\mathrm{Mx}$ and hair shaft derive from the epithelial bulge stem cells [24, 25, 27].

Mesenchymal stem cells in the tissue sheath serve as a reservoir for new DP cells. The DP determines the size of the anagen hair bulb, the duration of anagen and hair shaft diameter $[20,29,30]$. In adult hair, DP maintains the vascular system that provides the nutritional support and hormonal regulation required for hair growth [31]. 


\subsection{Hair Follicle Morphogenesis}

Follicle morphogenesis regularly occurs only during embryonic development, so each mammal is born with a fixed number of follicles that normally does not increase afterwards, although folliculoneogenesis can take place during wound healing [32-34].

\subsubsection{Hair Follicle Life Cycle}

The hair growth cycle describes the changing histological morphology of the shaft and of the follicle over time. Starting with anagen (rapid growth and hair shaft elongation), the follicle and its shaft progress through catagen (involution and apoptosis-driven regression), telogen (resting) and finally exogen (shedding) [20, $21,35]$.

In anagen, the growth phase of the hair cycle, hair undergoes morphological and molecular events similar to fetal HF morphogenesis [36, 37]. Many key molecular regulators of hair biology not only activate morphogenesis, but also regulate anagen induction and duration [38, 39]. In this phase, epithelial bulge stem cells differentiate into the various cell types that will reconstitute the entire hair shaft $[40,41]$. Hair shaft synthesis and melanin production in melanocytes (melanogenesis) [42], only take place in anagen. Pigmentation begins after the initiation of shaft formation and ends before this process is terminated, which causes the shaft to have an unpigmented tip and root. By the 7th week of gestation, melanocytes are already present in the human epidermis where they remain until hair morphogenesis starts, approximately 2 weeks later [43]. During HF morphogenesis, a few melanoblasts leave the epidermis and distribute randomly in the forming $\mathrm{HF}$ and in some sebaceous glands [44, 45]. Once the hair fiber is completely formed, melanocytes concentrate near the basal lamina surrounding the DP [44]. Anagen ends with a tightly regulated involution of the HF, which is accompanied with apoptosis and terminal differentiation of cells, a period designated as catagen [46].

The first sign of catagen is the cessation of melanin production in the hair bulb and apoptosis of follicular melanocytes, derived from melanocytic stem cells of the secondary hair germ [47]. Programmed cell death of these stem cells seems to play an important role in hair graying [48-50]. In contrast to what happens in the ORS and the Mx, no apoptosis occurs in the DP due to the presence of antiapoptotic protein BCL-2 $[37,46]$. During catagen, the DP condenses, moves upward beneath the HF bulge and halts its activity.

After regression, the HF enters telogen, a phase of relative quiescence regarding proliferation and biochemical activity. The follicle remains in this stage until it is reactivated by intra- and extrafollicular signals [51].

Once the growth cycle is complete and the phase of telogen reaches the end, the hair shaft will be shed. This process, exogen or teloptosis, is independent of a 
possible new HF cycle [52]. In fact, it is most common in mammals that a new hair shaft regrows before the resting shaft sheds, assuring the animal is never completely naked. Apart from normal development, in pathologies like trichostasis, where multiple shafts are formed and retained within the same HF, it also supports the thesis that follicle growth and shedding are independent events. Exogen ends when the shaft is released.

Recently, Rebora and Guarrera used the term kenogen to describe the interval in which the HF remains empty after the telogen hair has been shed and before a new anagen hair emerges. During kenogen the HF remains completely empty and possibly inactive. Frequency and duration of kenogen are greater in men and women with androgenic alopecia [53].

All body hairs undergo a similar life cycle, although its extent, the duration of its phases and the length of individual shafts vary between different body areas and between individuals, depending on genetic programming, genre, age and health status.

\subsection{Molecular Control of Hair Follicle Development and Cycling}

Epithelial-mesenchymal interactions are crucial in HF development and cycling. During normal embryonic development, interactions between epidermal keratinocytes and DP fibroblasts lead to the formation of the hair shaft. The most important factors regulating both developing and anagen follicles include the lymphoid-enhancer factor 1 (Lef1), Notch signaling pathway, Sonic hedgehog (Shh), bone morphogenetic proteins (BMPs), neurotrophins and several members of the Wnt family of proteins.

Bone morphogenetic proteins are expressed during embryonic development and postnatal life of nearly all mammalian organisms and play important roles in the regulation of both cell proliferation and differentiation [54]. BMP signaling inhibits induction of follicle development [35], and the neutralization of BMP-2 and BMP-4 activity by noggin stimulates the initiation of HF development $[55,56]$. However, the differentiation of keratinocytes into mature and cuticle cells is severely impaired if levels of BMPs decrease as these proteins restrict the proliferating population to the bulb region [57]. Recent studies reinforce the important role that the BMP signaling network plays in the development and homeostasis of HF structure through the activation and/or maintenance of stem cell populations $[58,59]$.

The Wnt signaling pathway has been implicated in multiple cellular events including the regulation of cell proliferation, cell fate, polarity, differentiation and pattern formation $[60,61]$. Wnts are divided at least into three groups according to their signal transduction pathways: the canonical pathway in which $\beta$-catenin stabilization occurs, the planar cell polarity (PCP) pathway and the $\mathrm{Wnt} / \mathrm{Ca}^{2+}$ 
pathway [62]. Canonical $\mathrm{Wnt} / \beta$-catenin signaling plays an important role in $\mathrm{HF}$ induction and fate [63-69], and expression of several Wnts, Wnt ligands and inhibitors is specifically elevated in developing and postnatal HFs [61, 70-72]. On the other hand, forced activation of $\beta$-catenin signaling promotes HF fate in both embryonic and postnatal skin [67, 73-75]. Recent studies also suggest that another pathway, the ectodysplasin signaling pathway, is critical for the induction and maintenance of placode [76, 77].

In a surprising report, Ito and collaborators revealed that HF can form de novo in adult mice after wounding [33], contrary to the belief that follicle neogenesis only occurred during embryonic development. This phenomenon is completely dependent on Wnt signaling, and overexpressing Wnt actually increases the number of HF formed. Interestingly, the cells forming the new $H F$ originate in the re-epithelialized interfollicular epidermis and not follicle stem cells.

In vertebrates, Shh is a member of the hedgehog $(\mathrm{Hh})$ family of secreted signaling molecules that play a crucial role in both embryogenesis and organogenesis [78, 79]. Shh is required for HF morphogenesis during embryogenesis and for regulating follicular growth and cycling in the adult. HF formation may start without Shh, but mature HFs fail to develop because hair germs cannot elongate into the dermis to form a hair peg and the DP does not mature [80-82]. In postnatal skin, Shh is relevant for hair cycling, its expression being up-regulated in early anagen. In line with this, treatment with Shh-blocking antibodies is known to cause reversible alopecia, as HF cannot cycle and arrest in telogen [83]. On the other hand, exogenous Hh stimulates the transition from resting (telogen) to growth (anagen) stage [84] and, in some settings, anticipates the start of anagen and promotes hair regrowth in the skin of mice with chemotherapy-induced alopecia $[85,86]$. These studies indicate a potential application of Hh modulation in control of hair density.

The Notch signaling pathway is also important for determining cell fate in HF development [87]. Notch signaling acts by blocking cell differentiation, which maintains the competence of undifferentiated cells $[88,89]$ in both the developing tooth and the HF to respond to inductive signals that determine their developmental fate [87, 90]. Based on expression studies in the HF, Notch may be a competence factor, as its pattern of expression in the HF appears to be restricted to cells that have left the proliferative pool but have yet to terminally differentiate [91, 92].

Although Notch activation is not required for HF formation in the embryo, blocking Notch signaling in postnatal epidermis results in conversion of HF into interfollicular epidermal cysts. In the absence of Notch signaling, the hair shaft still forms and contains appropriately positioned cells expressing markers for each fate; however, because IRS cells fail to adhere to each other, the follicular architecture cannot be sustained, which leads to the transformation of these aberrant HF into epidermal cysts [92-95]. Very recently, Demehri and Kopan [96] proposed that Notch acting on bi-potential bulge stem cells, or their uncommitted migratory descendents, plays an inhibitory role in preventing bulge stem cells from differentiating into epidermal cells, thus ensuring the follicular fate. 
It was also reported that Notch signaling, via its target gene Hes 1 , is essential for the maintenance of melanoblasts and adult melanocyte stem cells [97, 98]. Moreover, mice with a conditional deletion of RBP- $\mathrm{J}_{K}$ (Notch transcription mediator) display, soon after birth, impaired hair pigmentation and subsequent progression of hair graying. Specifically, Notch1 and Notch2 targeted deletion in melanocytes led to inactivation of the $R B P-J_{K}$ gene in a dose-dependent manner, and three intact alleles of Notch1 and Notch2 are required for preventing precocious hair graying [98]. Notch 3 and 4 are not implicated in this phenotype [99, 100].

Hormones, particularly androgens, are among the most important, although non-essential, modulators of hair growth. Androgens have paradoxically different effects on human HF depending on their body site. Androgens can stimulate hair growth on the face (beard), axilla, pubis and chest, where they are necessary for conversion of vellus hair to terminal hair, while they simultaneously can inhibit $\mathrm{HF}$ on parts of the scalp, converting terminal hair to vellus hair, causing balding in genetically susceptible individuals (for reviews, see [101, 102]).

Androgens, except for pubic and axillary follicles, require the intracellular enzyme $5 \alpha$-reductase to metabolize testosterone to its more potent metabolite $5 \alpha$ dihydrotestosterone (DHT). DHT then interacts with intracellular androgen receptors in the HF cells to modulate target gene transcription. The exact mechanism is not fully established, but Randal proposed the DP as the primary target $[103,104]$. In this model, androgens act directly on DP cells where they bind to androgen receptors and then initiate altered gene expression of regulatory factors modulating indirectly the period of time when hair is growing, size and activity of the DP, keratinocytes and melanocytes. The factors produced by these populations may be soluble paracrine factors and/or extracellular matrix factors, including insulin-like growth factor-1 (IGF-1) in growth stimulation [105], stem cell factor in altered pigmentation [102] and transforming growth factor- $\beta[106,107]$ and dickkopf 1 [108] in inhibition. The opposite effects of androgens on beard and scalp follicles probably reflect differences in androgen receptor content, which is higher in beard DP than in occipital hair DP [109] and/or $5 \alpha$-reductase activity, which is higher in beard than in scalp [110]. Recent observations suggest that the dermal sheath can also respond to androgens without the DP acting as an intermediary [111].

Several other hormones are implicated in the regulation of the hair growth cycle, including melatonin, prolactin, melanocyte-stimulating hormone (MSH), thyroid hormones and oestrogens. Prolactin is implicated in hair growth regulation in both mice and human [112-114]. Similarly, melatonin has been reported to promote hair growth in animals and in humans, where topical application of melatonin induced hair, probably through induction of anagen [115].

Human hair is deeply affected by the level of unbound thyroid hormones that have been described to prolong the duration of anagen, up-regulate the proliferation of Mx keratinocytes and also stimulate intrafollicular melanin synthesis [101, $116,117]$. On the other hand, several studies reveal that a significant percentage of patients presenting hair loss were diagnosed as suffering from hypothyroidism [118, 119]. 
Estrogens, namely $17 \beta$-estradiol, act mainly as hair growth inhibitors. Topical application to mice skin of $17 \beta$-estradiol inhibits hair growth and accelerates catagen, while antiestrogens promote early anagen [120,121]. A similar inhibitory effect on hair growth was observed in humans [122, 123]. Nevertheless, the exact role of estrogens in the regulation of the HF life cycle is still under debate.

Very recently, mammalian circadian clock genes such as Clock and Bmall were reported to be involved in the regulation of HF cycling [124], suggesting that modulation of hair growth may also be achieved by modulating circadian genes through control of the cell cycle.

Taken together, these studies suggest that the described genes and signaling pathways regulating $\mathrm{HF}$ morphogenesis and cycling can be reactivated and modulated in adult skin, creating new strategies for hair regeneration.

\section{Strategies for Cosmetic and Clinical Purposes}

\subsection{Treatments of Hair Growth Disorders: Room for Improvement}

The most common types of hair growth disorders are caused by aberrant HF cycling. One such disorder is androgenetic alopecia, characterized by a shortening of the anagen phase and a prolongation of telogen, combined with miniaturization of HF [125]. Hirsutism, on the other hand, is defined as the presence of excess terminal hairs in females in an adult male typical pattern [126]. To control the amount of hair produced for clinical purposes, the main strategy is to alter anagen duration either by shortening it in cases of hirsutism or by increasing it to correct alopecia.

The first-generation drugs used for hair growth control-topical minoxidil solution and oral finasteride-are the only FDA-approved drugs for this application. Minoxidil prolongs the anagen phase, and promotes growth and enlargement of follicles in telogen phase [30, 127]. The effects of minoxidil on human HF are nevertheless very contradictory. Some studies describe that, at low concentrations, minoxidil stimulates anagen in human follicles [128-130], while it can cause growth inhibition at high concentrations [128]. Other authors reported no effect at all [131].

Nevertheless, it is assumed that treatment with minoxidil lengthens and thickens the small vellus hairs and decreases shedding. Minoxidil is a potassium channel opener that causes vasorelaxation [132] and stimulates cutaneous blood flow to the scalp [133]. Minoxidil sulfate, a metabolite of minoxidil, is a potent vasodilator. Uptake and conversion of minoxidil to minoxidil sulfate occurs within the HF, suggesting a direct action on the follicle [134]. The most probable site of action of minoxidil is the DP [135], and the mechanism of action has been linked to its effects on the Kir6.1/SUR2B potassium channel expressed by the derma papilla [136-138]. 
Finasteride inhibits $5 \alpha$-reductase type II and decreases both serum and cutaneous dihydrotestosterone concentrations, thus inhibiting androgen-dependent miniaturization of HF [139]. The DP is probably also the target of finasteride. This drug is not effective in treating androgenetic alopecia in women, but it can be beneficial for women with hirsutism. Finasteride must be nevertheless used very cautiously because of its potential feminizing effects on male fetuses [104] and even in adult male patients where some cases of gynecomastia have been reported [140].

Latanoprost has also been found to reverse alopecia and induce increased growth of the eyelashes [141]. A beneficial role in reversing androgenetic alopecia has not, however, been found, and detailed studies regarding whether latanoprost or another prostaglandin analog could be clinically used are still lacking.

Additional current pharmacological therapies for hair disorders include a range of antiandrogens that block the intracellular androgen receptors [142]. The mechanisms by which all these compounds trigger hair cycle changes are not clear and justify further studies.

In recent years, the molecular characterization and isolation of living bulge stem cells along with the studies that revealed their high proliferative capacity and multipotency opened up new directions for their utilization in cutaneous (hair and skin) regenerative medicine $[24,25,143,144]$. This new approach suggests the control of hair characteristics from the living interior of the fiber. For this purpose, profound knowledge of genes and signaling pathways involved in hair disorders will permit specific modulation using, for example, RNA interference. miRNAs, which play a critical role in skin morphogenesis, were reported to be involved in the regulation of HFs development and cycling, but neither their expression nor their roles have been characterized yet [145]. This elucidation is crucial to develop new efficient treatments for hair disorders that do not cause hair damage or skin injuries, possibly using RNA interference for highly specific modulation of genes involved in these processes.

As proof of principle, we have achieved effective siRNA delivery and efficient modulation of a ubiquitous, highly expressed KRT1 gene in the epidermis of DBA/ 2J mice with a topical treatment (Araujo et al., submitted data).

Interestingly, topical application of cationic nanoliposomes loaded with specific siRNA has been tested as an effective approach for control of cutaneous melanomas [146], and siRNAs conjugated to cationized gelatin showed a positive effect on symptoms of alopecia in $\mathrm{C} 3 \mathrm{H} / \mathrm{HeJ}$ mice [147]. A promising line of research has been developed by Kerner and colleagues that proposes modulating androgen receptor expression with RNAi for hair and skin therapy [148, 149]. Nevertheless, this is still a very incipient area that promises to bring new and highly targeted strategies for skin and hair diseases.

$\mathrm{HF}$ as well as sweat glands are ideal targets for drug delivery and may represent an alternative to the intercellular route of skin permeation. HF, in contrast to the stratum corneum, represent an efficient long-term reservoir (up to 10 days) for topically applied substances, as their depletion occurs only through the slow processes of sebum production and hair growth [150-152]. The molecules that 
penetrate HF can also access the tissues surrounding the follicle and reach the blood circulation through the dense network of blood capillaries, thereby avoiding the stratum corneum barrier. For example, it was shown that when caffeine was included in a shampoo formulation, it was detectable in blood just 5 min after application [153]. Therefore, HF may serve not only as a major entry point, but also as a reservoir for dermally applied substances. In addition, HF also contained multiple target structures for innovative therapeutic approaches. These include specific cell populations in and around the HF, such as immune cells, stem cells and melanocytes, sebaceous glands and perifollicular blood vessels [154-156].

The sebaceous glands represent an important therapeutic site for follicular targeting since they are implicated in the aetiology of acne and androgenetic alopecia [157], as well as in other sebaceous gland dysfunctions [158]. Hueber et al. [157] suggested that the sebaceous glands specifically promoted the penetration of hydrocortisone and testosterone into the skin. Evidence suggests that topically applied compounds entrapped in liposomes accumulated not only in the $\mathrm{HF}$, but also in the sebaceous glands [159]. While the presence of lipophilic sebum may favor follicular uptake of lipophilic molecules, sebum production may, however, moderate drug transport, especially for hydrophilic drugs, functioning as a physical and a chemical barrier for drug penetration [160].

More efficient drug delivery vehicles are therefore being sought. Among the newly emerging concepts, drug delivery systems based on nano- and microparticles, which efficiently penetrate via the follicular route, are highly promising approaches. Nanospheres of different chemical natures are being tested for their capacity to facilitate the transport of substances to deeper layers of the skin, with obvious potential in topical delivery applications.

Another attractive targeting area within the HF is the bulge region. This region, including Mx cells, controls hair growth and pigmentation [161] and is responsible for follicle reconstitution due to the presence of stem cells with a high proliferative capacity and multipotency. The bulge region, in the ORS, has been described as the reservoir for keratinocyte stem cells in both humans and rodents [24, 26, 143, 162-164]. These cells are the target for gene delivery to facilitate long-term gene correction of congenital hair disorders or genetic skin disorders. Targeting of HF stem cells offers unique therapeutic options for genetic hair and skin therapy and regenerative medicine.

\subsection{Modifications of Hair Fiber Surface and Structure}

Hair's chemical and biological properties make it an ideal material for undergoing an infinite number of changes and treatments, from cosmetic to clinical applications.

Healthy and beautiful hair is desired, and the need for products that improve the look and feel of the hair surface has created a huge industry for hair care. Products such as shampoos and conditioners, along with damaging processes such as 
chemical dyeing and permanent wave or relaxing treatments, alter many hair properties, which results in damage to the hair fibre [165-167]. In recent years, many innovations have taken place, and new approaches for hair treatments have been reported in the literature to overcome this problem.

Unaltered human hair (virgin hair) has an isoelectric point near 3.67 [168]. Hence, during a normal hair washing procedure performed at neutral $\mathrm{pH}$ $(\mathrm{pH}>\mathrm{p} I)$, the surface of hair acquires negative charges. For this reason, most conditioning shampoos possess cationic polymers in order to counteract these negative charges, thereby improving hair texture and feel. Electrostatic interactions are believed to play a crucial role in the adsorption mechanism of such compounds [168]. However, these products are a small part of the polymer-based cosmetic products. Polymer-containing compositions represent the second-most common ingredient in cosmetic and personal care products. A diverse range of polymers is applied in this segment as film formers, fixatives, rheology modifiers, associative thickners, emulsifiers, stimuli-responsive agents, foam stabilizers and destabilizers, beneficial skin feel agents and antimicrobials [169].

Studies on protein-based formulations to treat hair fibres have also been widely explored. Several patents disclose compositions capable of restoring hair health by providing excellent finishing effects. Applications of proteins such as a watersoluble compound derived from a vegetable protein derivate [170], non-naturally occurring keratin proteins [171], a mixture of a hydrolyzed protein and an amino acid with an aliphatic side chain [172], and other hydrolyzed proteins [173, 174] are also examples within this category.

Several studies have been published regarding how to improve the structure of the keratin hair shaft mainly for cosmetic purposes. These studies take into account the keratinous structure of hair fibres and explore the potential benefit effects of amino acids and peptides in hair care applications [175-177]. Silva et al. [178] described the importance of peptide structure in hair penetration using conventional fluorescent microscopy. We have been investigating the protein disulfide isomerase (PDI) for the functionalization of keratinaceous surfaces with cysteinecontaining compounds (CCC) (Fernandes et al., submitted data). PDI is a multifunctional enzyme that catalyses formation and isomerization of disulfide bonds (disulfide shuffling) in a wide range of substrates. In vivo, PDI promotes the correct formation of disulfide bonds in proteins (oxidative folding), leading them to the native state. The CCCs were shown to penetrate inside the hair shaft and attach to the cortex without damaging hair. This approach can represent a promising strategy for the development of new hair care formulations with the ability to dye and restore the integrity of damaged hair (Fernandes et al., submitted data).

PDI has also been used for treatment of wool [179] and hair fibres [180]. King and Brockway [179] showed that PDI was able to restore part of the original properties on aged or harshly treated wool. The same enzyme was used by Brockway [180] to perform a curling, waving or straightening treatment safely under mild condition.

A method to gently and permanently relax or straighten hair was also attained by Presti [181] using a protease, kerA. This enzyme was found to cleave inter- 
peptide bonds, allowing the hair fiber to be relaxed or straightened with less damage to the fiber than would have occurred using traditional or existing straightening methods [181].

Humidity is an important factor when considering hair beauty and styling. Air humidity affects hair form and structure at the level of hydrogen bonds. A humidity increase of 30-70\% will augment by twofold the water content of hair, thereby increasing its volume by more than $20 \%$. This influx of water eventually causes the hair fibres to swell, which results in friction between fibres and an additional increase in volume and frizz, changing hair appearance [182]. To overcome this issue, scientists from Massachusetts Institute of Technology (MIT) developed a technology that reduces hair frizz using a polyfluoroester, a molecule smaller than the traditional ones used for frizz control. Because of its chemical nature, the formulation adheres tightly to the hair, promoting long-lasting resistance to moisture. Because of its low surface energy, this technology repels most other materials like water and oils. As an additional benefit, the low refractive index of the coating produces a unique, long-lasting shine and pop in the colour of the hair [183].

Today, people in ever-greater numbers alter their hair colour and appearance. However, the aggressiveness of the available techniques poses a big drawback to hair colouring. Commonly used hair dyeing compositions are driven by a mechanism of diffusion of small molecules into the hair fiber [184]. There are three different types of hair colouring agents: permanent, semi-permanent and temporary colourants. The permanent hair dyes are constituted of small dye precursors, able to penetrate into hair, which develop the colour within the hair shaft in the presence of high alkalinity and oxidative conditions. These dyes provide the best colouring results, but cause significant hair damage. The semi-permanent and temporary dyes are molecules too large to diffuse into the hair, therefore acting on the exterior of the fiber at the cuticle. This process does not harm the fiber because of the absence of alkaline oxidative conditions, but fails in terms of colour durability [166]. For this reason, the development of a colouring agent that provides the durability of the permanent hair dyes without the use of oxidizing agents that damage hair is highly desirable.

It is generally accepted that penetration of chemicals into hair occurs through intercellular diffusion, i.e., by adsorption onto the keratin substrate. Faucher and Goddard [185] have shown that the amount of polymer adsorbed on the hair surface increased with decreasing molecular weight. Similarly, low molecular weight compounds might also penetrate the hair shaft, at the cortex level, since the diffusion process is greatly facilitated when hair is exposed to water. Low molecular weight compounds are, however, only retained while the hair is dry because further contact with water opens the cuticle scales, facilitating their escaping. Recent solutions to this problem rely on the use of hair-binding peptides coupled to dyes or pigments that are able to penetrate into the hair shaft, although they lack the required durability for long lasting colour effects. Huang et al. [186] have tested a hair-binding peptide coupled to carbon black and the use of chemically functionalized carbon nanotubes that provided an enhanced interaction with 
the hair, resulting in a more durable hair colouring effect. Nevertheless, more durable hair colourants are still needed.

For this reason, there have been attempts to enhance the binding of the cosmetic agent to hair. Richardson et al. [187] describe the covalent attachment of cosmetic agents to hair using transglutaminases. These enzymes promote the crosslinking of the cosmetic agent's amine to the glutamine residues in hair. Similarly, Green et al. [188] describe the use of the enzyme lysine oxidase to covalently attach cosmetic agents to hair.

Despite all the research for cosmetic applications, conventional products are still being used, with small improvements. Formulation requirements imply very strict criteria for dye/product selection. The remaining problem is achieving perfect compatibility in all respects between the dyes/products and the various other constituents of the products.

\section{Final Remarks}

Hirsutism, graying, alopecia and other disorders of human HFs have dramatic effects on the appearance, socio-cultural status and self-esteem of the affected individuals. The most current treatments available are very aggressive to hair and potentially to human health. In order to solve these problems, new and more efficient approaches are required.

Much progress has been made in understanding the genetic basis and molecular pathways activated during HF embryogenesis, cycling, disorders and the ageing process. HFs are a rich source of stem cells. The recent advances in the isolation, gene expression profile and propagation of stem cells could lead to the modulation of these cells with therapeutic purposes in the treatment of alopecia, wounds, burns, carcinogenesis and even ageing.

The potential specific targeting of different HF-associated cells, namely DP and immune cells, by bioactive compounds, along with effective follicular delivery systems will allow the development of home-based procedures for the maintenance and treatment of hair and scalp disorders.

\section{References}

1. Franbourg A et al (2003) Current research on ethnic hair. J Am Acad Dermatol 48(6 Suppl 1):S115-S119

2. Wolfram LJ (2003) Human hair: a unique physicochemical composite. J Am Acad Dermatol 48(6 Suppl 1):S106-S114

3. Swift JA (1999) Human hair cuticle: biologically conspired to the owner's advantage. J Cosmet Sci 50:23-47

4. Feughelman M (1997) Mechanical properties and structure of alpha-keratin fibres. UNSW Press, Sidney 
5. O'Connor SD, Komisarek KL, Baldeschwieler JD (1995) Atomic force microscopy of human hair cuticles: a microscopic study of environmental effects on hair morphology. J Investig Dermatol 105(1):96-99

6. Plowman JE (2007) The proteomics of keratin proteins. J Chromatogr B 849(1-2):181-189

7. Bhushan B (2008) Nanoscale characterization of human hair and hair conditioners. Prog Mater Sci 53(4):585-710

8. Smith TA, Parry DAD (2007) Sequence analyses of Type I and Type II chains in human hair and epithelial keratin intermediate filaments: promiscuous obligate heterodimers, Type II template for molecule formation and a rationale for heterodimer formation. J Struct Biol 158(3):344-357

9. Zimek A, Weber K (2006) The organization of the keratin I and II gene clusters in placental mammals and marsupials show a striking similarity. Eur J Cell Biol 85(2):83-89

10. Parry DAD et al. (2006) Human hair keratin-associated proteins: sequence regularities and structural implications. J Struct Biol 155(2):361-369

11. Jones LN et al. (1997) Intermediate filament structure: hard [alpha]-keratin. Biophys Chem 68(1-3):83-93

12. Wysocki AP, Mann GV, Stare FJ (1954) The cystine and methionine content of the hair of malnourished children. Am J Clin Nutr 2(4):243-245

13. Wilson RH, Lewis HB (1927) The cystine content of hair and other epidermal tissues. J Biol Chem 73(2):543-553

14. Block RJ, Bolling D, Brand FC, Schein A (1939) The composition of keratins. The amino acid composition of hair, wool, horn, and other eukeratins. J Biol Chem 128(1):181-186

15. Danciulescu C, Nick B, Wortmann FJ (2004) Structural stability of wild type and mutated $\alpha$ keratin fragments: molecular dynamics and free energy calculations. Biomacromolecules $5(6): 2165-2175$

16. Plowman JE (2003) Proteomic database of wool components. J Chromatogr B Anal Technol Biomed Life Sci 787:63-76

17. Borges CR et al (2001) Relationship of melanin degradation products to actual melanin content: application to human hair. Anal Biochem 290(1):116-125

18. Wolfram LJ (1981)The reactivity of human hair, in hair research, status and future aspects. In: Orfanos CE, Montagna W, Stuttgen G (eds) Springer, Heidelberg, pp 479-500

19. Nappe C, Kermici M (1988) Electrophoretic analysis of alkylated proteins of human hair from various ethnic groups. J Soc Cosmet Chem 40:91-99

20. Krause K, Foitzik K (2006) Biology of the hair follicle: the basics. Semin Cutan Med Surg 25(1):2-10

21. Fuchs E et al (2001) At the roots of a never-ending cycle. Dev Cell 1(1):13-25

22. Barrandon Y, Green H (1987) Three clonal types of keratinocyte with different capacities for multiplication. Proc Natl Acad Sci USA 84(8):2302-2306

23. Oshima $\mathrm{H}$ et al (2001) Morphogenesis and renewal of hair follicles from adult multipotent stem cells. Cell 104(2):233-245

24. Morris RJ et al (2004) Capturing and profiling adult hair follicle stem cells. Nat Biotechnol 22(4):411-417

25. Blanpain C et al (2004) Self-renewal, multipotency, and the existence of two cell populations within an epithelial stem cell niche. Cell 118(5):635-648

26. Claudinot $\mathrm{S}$ et al (2005) Long-term renewal of hair follicles from clonogenic multipotent stem cells. Proc Natl Acad Sci USA 102(41):14677-14682

27. Ohyama M (2007) Hair follicle bulge: a fascinating reservoir of epithelial stem cells. J Dermatol Sci 46(2):81-89

28. Birbeck MS, Mercer EH (1957) The electron microscopy of the human hair follicle. I. Introduction and the hair cortex. J Biophys Biochem Cytol 3(2):203-214

29. Jahoda CA, Reynolds AJ (1996) Dermal-epidermal interactions. Adult follicle-derived cell populations and hair growth. Dermatol Clin 14(4):573-583

30. Paus R, Cotsarelis G (1999) The biology of hair follicles. N Engl J Med 341(7):491-497 
31. Mecklenburg L et al (2000) Active hair growth (anagen) is associated with angiogenesis. J Invest Dermatol 114(5):909-916

32. Kligman AM, Strauss JS (1956) The formation of vellus hair follicles from human adult epidermis. J Invest Dermatol 27(1):19-23

33. Ito $\mathrm{M}$ et al (2007) Wnt-dependent de novo hair follicle regeneration in adult mouse skin after wounding. Nature 447(7142):316-320

34. Chuong CM, Cotsarelis G, Stenn K (2007) Defining hair follicles in the age of stem cell bioengineering. J Invest Dermatol 127(9):2098-2100

35. Botchkarev VA, Paus R (2003) Molecular biology of hair morphogenesis: development and cycling. J Exp Zool B Mol Dev Evol 298(1):164-180

36. Chase HB (1954) Growth of the hair. Physiol Rev 34(1):113-126

37. Muller-Rover S et al (2001) A comprehensive guide for the accurate classification of murine hair follicles in distinct hair cycle stages. J Invest Dermatol 117(1):3-15

38. Millar SE (2002) Molecular mechanisms regulating hair follicle development. J Invest Dermatol 118(2):216-225

39. Schmidt-Ullrich R, Paus R (2005) Molecular principles of hair follicle induction and morphogenesis. Bioessays 27(3):247-261

40. Reynolds AJ, Jahoda CA (1991) Hair follicle stem cells? A distinct germinative epidermal cell population is activated in vitro by the presence of hair dermal papilla cells. J Cell Sci 99(2):373-385

41. Panteleyev AA, Jahoda CA, Christiano AM (2001) Hair follicle predetermination. J Cell Sci 114(Pt 19):3419-3431

42. Passeron T, Mantoux F, Ortonne JP (2005) Genetic disorders of pigmentation. Clin Dermatol 23(1):56-67

43. Holbrook KA et al (1989) The appearance, density and distribution of melanocytes in human embryonic and fetal skin revealed by the anti-melanoma monoclonal antibody, HMB-45. Anat Embryol Berl 180(5):443-455

44. Hashimoto K (1971) The ultrastructure of the skin of human embryos. 8. Melanoblast and intrafollicular melanocyte. J Anat 108(Pt 1):99-108

45. Kukita A, Sato S, Ito K (1974) Electron microscopic observations of melanin transfer in human skin. Evidence for indirect melanin transfer. Acta Derm Venereol 54(5):349-357

46. Lindner $\mathrm{G}$ et al (1997) Analysis of apoptosis during hair follicle regression (catagen). Am J Pathol 151(6):1601-1617

47. Slominski A et al (1994) Melanogenesis during the anagen-catagen-telogen transformation of the murine hair cycle. J Invest Dermatol 102(6):862-869

48. Nishimura EK, Granter SR, Fisher DE (2005) Mechanisms of hair graying: incomplete melanocyte stem cell maintenance in the niche. Science 307(5710):720-724

49. Magerl $\mathrm{M}$ et al (2001) Patterns of proliferation and apoptosis during murine hair follicle morphogenesis. J Invest Dermatol 116(6):947-955

50. Tobin DJ et al (1998) Do hair bulb melanocytes undergo apoptosis during hair follicle regression (catagen)? J Invest Dermatol 111(6):941-947

51. Saitoh M, Uzuka M, Sakamoto M (1970) Human hair cycle. J Invest Dermatol 54(1):65-81

52. Pierard-Franchimont C, Pierard GE (2001) Teloptosis, a turning point in hair shedding biorhythms. Dermatology 203(2):115-117

53. Rebora A, Guarrera M (2002) Kenogen. A new phase of the hair cycle? Dermatology 205(2):108-110

54. Hogan BL (1996) Bmps: multifunctional regulators of mammalian embryonic development. Harvey Lect 92:83-98

55. Botchkarev VA et al (1999) Noggin is a mesenchymally derived stimulator of hair-follicle induction. Nat Cell Biol 1(3):158-164

56. Botchkarev VA et al (2002) Modulation of BMP signaling by noggin is required for induction of the secondary (nontylotrich) hair follicles. J Invest Dermatol 118(1):3-10

57. Kulessa H, Turk G, Hogan BL (2000) Inhibition of Bmp signaling affects growth and differentiation in the anagen hair follicle. EMBO J 19(24):6664-6674 
58. Zhang $\mathrm{J}$ et al (2006) Bone morphogenetic protein signaling inhibits hair follicle anagen induction by restricting epithelial stem/progenitor cell activation and expansion. Stem Cells 24(12):2826-2839

59. Plikus MV et al (2008) Cyclic dermal BMP signalling regulates stem cell activation during hair regeneration. Nature 451(7176):340-344

60. Cadigan KM, Nusse R (1997) Wnt signaling: a common theme in animal development. Genes Dev 11(24):3286-3305

61. DasGupta R, Fuchs E (1999) Multiple roles for activated LEF/TCF transcription complexes during hair follicle development and differentiation. Development 126(20):4557-4568

62. Du SJ et al (1995) Identification of distinct classes and functional domains of Wnts through expression of wild-type and chimeric proteins in Xenopus embryos. Mol Cell Biol 15(5):2625-2634

63. Logan CY, Nusse R (2004) The Wnt signaling pathway in development and disease. Annu Rev Cell Dev Biol 20:781-810

64. Reya T, Clevers H (2005) Wnt signalling in stem cells and cancer. Nature 434(7035):843-850

65. Clevers H (2006) Wnt/beta-catenin signaling in development and disease. Cell 127(3): 469-480

66. Andl T et al (2002) WNT signals are required for the initiation of hair follicle development. Dev Cell 2(5):643-653

67. Gat U et al (1998) De Novo hair follicle morphogenesis and hair tumors in mice expressing a truncated beta-catenin in skin. Cell 95(5):605-614

68. Huelsken $\mathrm{J}$ et al (2001) beta-Catenin controls hair follicle morphogenesis and stem cell differentiation in the skin. Cell 105(4):533-545

69. Lo Celso C, Prowse DM, Watt FM (2004) Transient activation of beta-catenin signalling in adult mouse epidermis is sufficient to induce new hair follicles but continuous activation is required to maintain hair follicle tumours. Development 131(8):1787-1799

70. Maretto $\mathrm{S}$ et al (2003) Mapping Wnt/beta-catenin signaling during mouse development and in colorectal tumors. Proc Natl Acad Sci USA 100(6):3299-3304

71. Reddy S et al (2001) Characterization of Wnt gene expression in developing and postnatal hair follicles and identification of Wnt5a as a target of Sonic hedgehog in hair follicle morphogenesis. Mech Dev 107(1-2):69-82

72. Kobielak K et al (2007) Loss of a quiescent niche but not follicle stem cells in the absence of bone morphogenetic protein signaling. Proc Natl Acad Sci USA 104(24):10063-10068

73. Narhi K et al (2008) Sustained epithelial beta-catenin activity induces precocious hair development but disrupts hair follicle down-growth and hair shaft formation. Development 135(6): 1019-1028

74. Zhang CP, Fu XB (2008) Therapeutic potential of stem cells in skin repair and regeneration. Chin J Traumatol 11(4):209-221

75. Suzuki K et al (2009) Embryonic hair follicle fate change by augmented beta-catenin through Shh and Bmp signaling. Development 136(3):367-372

76. Schmidt-Ullrich $\mathrm{R}$ et al (2006) NF-kappaB transmits Eda A1/EdaR signalling to activate Shh and cyclin D1 expression, and controls post-initiation hair placode down growth. Development 133(6):1045-1057

77. Zhang YV et al (2009) Distinct self-renewal and differentiation phases in the niche of infrequently dividing hair follicle stem cells. Cell Stem Cell 5(3):267-278

78. McMahon AP, Ingham PW, Tabin CJ (2003) Developmental roles and clinical significance of hedgehog signaling. Curr Top Dev Biol 53:1-114

79. Ingham PW, Placzek M (2006) Orchestrating ontogenesis: variations on a theme by sonic hedgehog. Nat Rev Genet 7(11):841-850

80. St-Jacques B et al (1998) Sonic hedgehog signaling is essential for hair development. Curr Biol 8(19):1058-1068

81. Chiang C et al (1999) Essential role for Sonic hedgehog during hair follicle morphogenesis. Dev Biol 205(1):1-9 
82. Karlsson L, Bondjers C, Betsholtz C (1999) Roles for PDGF-A and sonic hedgehog in development of mesenchymal components of the hair follicle. Development 126(12):2611-2621

83. Wang LC et al (2000) Regular articles: conditional disruption of hedgehog signaling pathway defines its critical role in hair development and regeneration. J Invest Dermatol 114(5):901-908

84. Iseki S et al (1996) Sonic hedgehog is expressed in epithelial cells during development of whisker, hair, and tooth. Biochem Biophys Res Commun 218(3):688-693

85. Sato N, Leopold PL, Crystal RG (2001) Effect of adenovirus-mediated expression of Sonic hedgehog gene on hair regrowth in mice with chemotherapy-induced alopecia. J Natl Cancer Inst 93(24):1858-1864

86. Sato $\mathrm{T}$ et al (1999) Minoxidil increases 17 beta-hydroxysteroid dehydrogenase and 5 alphareductase activity of cultured human dermal papilla cells from balding scalp. J Dermatol Sci 19(2):123-125

87. Kopan R, Weintraub H (1993) Mouse notch: expression in hair follicles correlates with cell fate determination. J Cell Biol 121(3):631-641

88. Mitsiadis TA et al (1997) Mouse Serrate-1 (Jagged-1): expression in the developing tooth is regulated by epithelial-mesenchymal interactions and fibroblast growth factor-4. Development 124(8):1473-1483

89. Mitsiadis TA et al (1995) Expression of the heparin-binding cytokines, midkine (MK) and HB-GAM (pleiotrophin) is associated with epithelial-mesenchymal interactions during fetal development and organogenesis. Development 121(1):37-51

90. Weinmaster G, Roberts VJ, Lemke G (1991) A homolog of Drosophila Notch expressed during mammalian development. Development 113(1):199-205

91. Cai J et al (2009) Genetic interplays between Msx2 and Foxn1 are required for Notch1 expression and hair shaft differentiation. Dev Biol 326(2):420-430

92. Pan Y et al (2004) gamma-secretase functions through Notch signaling to maintain skin appendages but is not required for their patterning or initial morphogenesis. Dev Cell 7(5):731-743

93. Yamamoto N et al (2003) Notch/RBP-J signaling regulates epidermis/hair fate determination of hair follicular stem cells. Curr Biol 13(4):333-338

94. Vauclair S et al (2005) Notch1 is essential for postnatal hair follicle development and homeostasis. Dev Biol 284(1):184-193

95. Estrach $\mathrm{S}$ et al (2006) Jagged 1 is a beta-catenin target gene required for ectopic hair follicle formation in adult epidermis. Development 133(22):4427-4438

96. Demehri S, Kopan R (2009) Notch signaling in bulge stem cells is not required for selection of hair follicle fate. Development 136(6):891-896

97. Moriyama $\mathrm{M}$ et al (2006) Notch signaling via Hes1 transcription factor maintains survival of melanoblasts and melanocyte stem cells. J Cell Biol 173(3):333-339

98. Schouwey K et al (2007) Notch1 and Notch2 receptors influence progressive hair graying in a dose-dependent manner. Dev Dyn 236(1):282-289

99. Krebs LT et al (2003) Characterization of Notch3-deficient mice: normal embryonic development and absence of genetic interactions with a Notch1 mutation. Genesis 37(3):139-143

100. Louvi A, Artavanis-Tsakonas S (2006) Notch signalling in vertebrate neural development. Nat Rev Neurosci 7(2):93-102

101. Randall VA (2007) Hormonal regulation of hair follicles exhibits a biological paradox. Semin Cell Dev Biol 18(2):274-285

102. Randall VA (2008) Androgens and hair growth. Dermatol Ther 21(5):314-328

103. Randall VA et al (1991) Androgens and the hair follicle. Cultured human dermal papilla cells as a model system. Ann N Y Acad Sci 642:355-375

104. Randall VA et al (1994) Androgen action in cultured dermal papilla cells from human hair follicles. Skin Pharmacol 7(1-2):20-26 
105. Itami S, Kurata S, Takayasu S (1995) Androgen induction of follicular epithelial cell growth is mediated via insulin-like growth factor-I from dermal papilla cells. Biochem Biophys Res Commun 212(3):988-994

106. Inui $\mathrm{S}$ et al (2002) Androgen-inducible TGF-beta1 from balding dermal papilla cells inhibits epithelial cell growth: a clue to understand paradoxical effects of androgen on human hair growth. FASEB J 16(14):1967-1969

107. Hibino T, Nishiyama T (2004) Role of TGF-beta2 in the human hair cycle. J Dermatol Sci 35(1):9-18

108. Kwack MH et al (2008) Dihydrotestosterone-inducible dickkopf 1 from balding dermal papilla cells causes apoptosis in follicular keratinocytes. J Invest Dermatol 128(2):262-269

109. Sawaya ME, Price VH (1997) Different levels of 5alpha-reductase type I and II, aromatase, and androgen receptor in hair follicles of women and men with androgenetic alopecia. J Invest Dermatol 109(3):296-300

110. Ando $\mathrm{Y}$ et al (1999) Expression of mRNA for androgen receptor, 5alpha-reductase and 17beta-hydroxysteroid dehydrogenase in human dermal papilla cells. $\mathrm{Br} \mathrm{J}$ Dermatol 141(5):840-845

111. Asada $\mathrm{Y}$ et al (2001) 5 alpha-reductase type 2 is constitutively expressed in the dermal papilla and connective tissue sheath of the hair follicle in vivo but not during culture in vitro. J Clin Endocrinol Metab 86(6):2875-2880

112. Craven AJ et al (2006) Prolactin delays hair regrowth in mice. J Endocrinol 191(2):415-425

113. Craven AJ et al (2001) Prolactin signaling influences the timing mechanism of the hair follicle: analysis of hair growth cycles in prolactin receptor knockout mice. Endocrinology 142(6):2533-2539

114. Foitzik $\mathrm{K}$ et al (2006) Human scalp hair follicles are both a target and a source of prolactin, which serves as an autocrine and/or paracrine promoter of apoptosis-driven hair follicle regression. Am J Pathol 168(3):748-756

115. Fischer TW et al (2004) Melatonin increases anagen hair rate in women with androgenetic alopecia or diffuse alopecia: results of a pilot randomized controlled trial. Br J Dermatol 150(2):341-345

116. Redondo P et al (2007) Repigmentation of gray hair after thyroid hormone treatment. Actas Dermosifiliogr 98(9):603-610

117. van Beek $\mathrm{N}$ et al (2008) Thyroid hormones directly alter human hair follicle functions: anagen prolongation and stimulation of both hair matrix keratinocyte proliferation and hair pigmentation. J Clin Endocrinol Metab 93(11):4381-4388

118. Freinkel RK, Freinkel N (1972) Hair growth and alopecia in hypothyroidism. Arch Dermatol 106(3):349-352

119. Schell H et al (1991) Cell cycle kinetics of human anagen scalp hair bulbs in thyroid disorders determined by DNA flow cytometry. Dermatologica 182(1):23-26

120. Chanda $S$ et al (2000) 17beta-estradiol and ICI-182780 regulate the hair follicle cycle in mice through an estrogen receptor-alpha pathway. Am J Physiol Endocrinol Metab 278(2):E202-E210

121. Oh HS, Smart RC (1996) An estrogen receptor pathway regulates the telogen-anagen hair follicle transition and influences epidermal cell proliferation. Proc Natl Acad Sci USA 93(22): 12525-12530

122. Kondo S, Hozumi Y, Aso K (1990) Organ culture of human scalp hair follicles: effect of testosterone and oestrogen on hair growth. Arch Dermatol Res 282(7):442-445

123. Conrad F, Paus R (2004) Estrogens and the hair follicle. J Dtsch Dermatol Ges 2(6):412-423

124. Lin KK et al (2009) Circadian clock genes contribute to the regulation of hair follicle cycling. PLoS Genet 5:1000573

125. Sinclair RD, Dawber RP (2001) Androgenetic alopecia in men and women. Clin Dermatol 19(2):167-178

126. Azziz R (2003) The evaluation and management of hirsutism. Obstet Gynecol 101(5 Pt 1):995-1007 
127. Mori O, Uno H (1990) The effect of topical minoxidil on hair follicular cycles of rats. J Dermatol 17(5):276-281

128. Philpott M, Green MR, Kealey T (1989) Studies on the biochemistry and morphology of freshly isolated and maintained rat hair follicles. J Cell Sci 93(3):409-418

129. Han JH et al (2004) Effect of minoxidil on proliferation and apoptosis in dermal papilla cells of human hair follicle. J Dermatol Sci 34(2):91-98

130. Kwon OS et al (2006) Human hair growth ex vivo is correlated with in vivo hair growth: selective categorization of hair follicles for more reliable hair follicle organ culture. Arch Dermatol Res 297(8):367-371

131. Magerl M et al (2004) Limitations of human occipital scalp hair follicle organ culture for studying the effects of minoxidil as a hair growth enhancer. Exp Dermatol 13(10):635-642

132. Weston AH, Edwards G (1992) Recent progress in potassium channel opener pharmacology. Biochem Pharmacol 43(1):47-54

133. Wester RC et al (1984) Minoxidil stimulates cutaneous blood flow in human balding scalps: pharmacodynamics measured by laser Doppler velocimetry and photopulse plethysmography. J Invest Dermatol 82(5):515-517

134. Baker CA, Uno H, Johnson GA (1994) Minoxidil sulfation in the hair follicle. Skin Pharmacol 7(6):335-339

135. Headington JT (1987) Hair follicle biology and topical minoxidil: possible mechanisms of action. Dermatologica 175(2):19-22

136. Buhl AE et al (1992) Potassium channel conductance: a mechanism affecting hair growth both in vitro and in vivo. J Invest Dermatol 98(3):315-319

137. Shorter K et al (2008) Human hair follicles contain two forms of ATP-sensitive potassium channels, only one of which is sensitive to minoxidil. FASEB J 22(6):1725-1736

138. Davies GC et al (2005) Novel and established potassium channel openers stimulate hair growth in vitro: implications for their modes of action in hair follicles. J Invest Dermatol 124(4):686-694

139. Johnstone MA (1997) Hypertrichosis and increased pigmentation of eyelashes and adjacent hair in the region of the ipsilateral eyelids of patients treated with unilateral topical latanoprost. Am J Ophthalmol 124(4):544-547

140. Ramot $Y$ et al (2009) Endocrine controls of keratin expression. Bioessays 31(4):389-399

141. Mansberger SL, Cioffi GA (2000) Eyelash formation secondary to latanoprost treatment in a patient with alopecia. Arch Ophthalmol 118(5):718-719

142. Blume-Peytavi U, Hahn S (2008) Medical treatment of hirsutism. Dermatol Ther 21(5):329-339

143. Taylor $\mathrm{G}$ et al (2000) Involvement of follicular stem cells in forming not only the follicle but also the epidermis. Cell 102(4):451-461

144. Tumbar $\mathrm{T}$ et al (2004) Defining the epithelial stem cell niche in skin. Science 303(5656):359-363

145. Yi R et al (2006) Morphogenesis in skin is governed by discrete sets of differentially expressed microRNAs. Nat Genet 38(3):356-362

146. Tran MA et al (2008) Targeting V600EB-Raf and Akt3 using nanoliposomal-small interfering RNA inhibits cutaneous melanocytic lesion development. Cancer Res 68(18):7638-7649

147. Nakamura $\mathrm{M}$ et al (2008) Controlled delivery of T-box21 small interfering RNA ameliorates autoimmune alopecia (Alopecia Areata) in a $\mathrm{C} 3 \mathrm{H} / \mathrm{HeJ}$ mouse model. Am J Pathol 172(3):650-658

148. Dugour A et al (2009) Silencing the androgen receptor: new skills for antiandrogen oligonucleotide skin and hair therapy. J Dermatol Sci 54(2):123-125

149. Balana ME et al (2004) Antiandrogen oligonucleotides: active principles in hair- and skinderived culture cells. J Drugs Dermatol 3(3):287-294

150. Teichmann A et al (2006) Semiquantitative determination of the penetration of a fluorescent hydrogel formulation into the hair follicle with and without follicular closure by microparticles by means of differential stripping. Skin Pharmacol Physiol 19(2):101-105 
151. Lademann $\mathbf{J}$ et al (2006) Penetration studies of topically applied substances: optical determination of the amount of stratum corneum removed by tape stripping. J Biomed Opt 11(5):054026

152. Lademann J et al (2008) Hair follicles_an efficient storage and penetration pathway for topically applied substances. Summary of recent results obtained at the Center of Experimental and Applied Cutaneous Physiology, Charite-Universitatsmedizin Berlin, Germany. Skin Pharmacol Physiol 21(3):150-155

153. Otberg $\mathrm{N}$ et al (2007) Follicular penetration of topically applied caffeine via a shampoo formulation. Skin Pharmacol Physiol 20(4):195-198

154. Gupta S, Domashenko A, Cotsarelis G (2001) The hair follicle as a target for gene therapy. Eur J Dermatol 11(4):353-356

155. Nishimura EK et al (2002) Dominant role of the niche in melanocyte stem-cell fate determination. Nature 416(6883):854-860

156. Vogt A et al (2005) Follicular targeting - a promising tool in selective dermatotherapy. J Investig Dermatol Symp Proc 10(3):252-255

157. Hueber F, Wepierre J, Schaefer H (1992) Role of transepidermal and transfollicular routes in percutaneous absorption of hydrocortisone and testosterone: in vivo study in the hairless rat. Skin Pharmacol 5(2):99-107

158. Rolland A et al (1993) Site-specific drug delivery to pilosebaceous structures using polymeric microspheres. Pharm Res 10(12):1738-1744

159. Bernard E, Dubois JL, Wepierre J (1997) Importance of sebaceous glands in cutaneous penetration of an antiandrogen: target effect of liposomes. J Pharm Sci 86(5):573-578

160. Meidan VM, Bonner MC, Michniak BB (2005) Transfollicular drug delivery-is it a reality? Int J Pharm 306(1-2):1-14

161. Ohyama M, Vogel JC (2003) Gene delivery to the hair follicle. J Investig Dermatol Symp Proc 8(2):204-206

162. Cotsarelis G, Sun TT, Lavker RM (1990) Label-retaining cells reside in the bulge area of pilosebaceous unit: implications for follicular stem cells, hair cycle, and skin carcinogenesis. Cell 61(7):1329-1337

163. Lyle $\mathrm{S}$ et al (1998) The C8/144B monoclonal antibody recognizes cytokeratin 15 and defines the location of human hair follicle stem cells. J Cell Sci 111(21):3179-3188

164. Ohyama $\mathrm{M}$ et al (2006) Characterization and isolation of stem cell-enriched human hair follicle bulge cells. J Clin Invest 116(1):249-260

165. Gray J, Hair care and hair care products. Clinics in Dermatology. 19(2): 227-236

166. Bolduc C, Shapiro J (2001) Hair care products: waving, straightening, conditioning, and coloring. Clin Dermatol 19(4):431-436

167. Dawber R (1996) Hair: its structure and response to cosmetic preparations. Clin Dermatol 14(1):105-112

168. Regismond STA et al (1999) Fluorescence microscopy observation of the adsorption onto hair of a fluorescently labeled cationic cellulose ether. Langmuir 15(8):3007-3010

169. Morgan ES, Havelka OK, Lochhead YR (2007) Cosmetic nanotechnology: polymers and colloids in cosmetics. In: ACS symposium series 961. A.C. Society, Washington DC

170. Michiki K (1998) Hair cosmetic composition. Patent JP10251127, Henkel Japan KK

171. Ensley BD (2001) Recombinant hair treatment compositions. US Patent 20010006664

172. Cornwell PA, Ellis FA, Finel CM (2003) Hair treatment compositions. Patent WO/2003/ 045340, Unilever PL

173. Ansmann DA (1985) Cosmetic preparations with almond protein hydrolysate. European Patent

174. Cannell D, Nguyen N (1998) Composition for treating hair. Patent WO/1998/051265, L'oreal

175. Roddick-Lanzilotta A et al (2007) New keratin isolates: actives for natural hair protection. J Cosmet Sci 58(4):405-411

176. Cochran S, Brockman T (2007) A cosmetic ingredient innovation for the stabilization and delivery of volatile fluoroether with cosmetic applications. J Cosmet Sci 58(4):413-419 
177. Oshimura E, Abe H, Oota R (2007) Hair and amino acids: the interactions and the effects. J Cosmet Sci 58(4):347-357

178. Silva CJ, Vasconcelos A, Cavaco-Paulo A (2007) Peptide structure: its effect on penetration into human hair. J Cosmet Sci 58(4):339-346

179. King RD, Brockway BE (1992) Treatment of wool materials. The University of Reading, Reading

180. Brockway BE (1992) Treatment of hair. The University of Reading, Reading

181. Presti RA (2010) Enzymatic hair relaxing and straightening. US Patent 20100012142

182. Schueller R, Romanowski P (1998) The science of reactive hair-care products. Cosmet Toilet 113:39-44

183. (MIT), M.I.o.T. MIT Scientists Develop Polyfluoroester Technology for Hair Care (2008). http://www.cosmeticsandtoiletries.com/formulating/category/haircare/29245519.html?utm_ source=Most+Read\&utm_medium=website\&utm_campaign=Most + Read]

184. Pille L, Church JS, Gilbert RG (1998) Adsorption of amino-functional polymer particles onto keratin fibres. J Colloid Interface Sci 198(2):368-377

185. Faucher JA, Goddard ED (1976) Sorption of a cationic polymer by stratum corneum. J Soc Cosmet Chem 27:543-553

186. Huang X, Kobos RK, XU G (2005) Peptide-based carbon nanotube hair colorants and their use in hair colorant and cosmetic compositions. Patent WO/2005/117537, E.I. Dupont De Nemours And Company

187. Richardson NK (1994) Covalent bonding of active agents to skin, hair or nails. US Patent 5490980, Chesebrough-Pond's USA Co., Division of Conopco, Inc

188. Green HC, George D, Compton, BJ, Dijan P (1999) Attaching agents to tissue with transglutaminase and a transglutaminase substrate. United States 